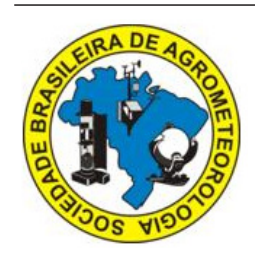

\title{
Balanço de radiação da cana-de-açúcar irrigada por gotejamento subsuperficial no submédio do Vale São Francisco
} \author{
Souza $^{3}$, Mario de Miranda Vilas Boas Ramos Leitao ${ }^{4}$ \\ ${ }^{1}$ Mestre, CPGEA, UNIVASF, Juazeiro-BA, j.francarmo@gmail.com \\ ${ }^{2}$ Pesquisadora, Embrapa Semiárido, Petrolina-PE, magnamoura@embrapa.br \\ ${ }^{3}$ Professor, UFRPE/UAST, Serra Talhada-PE, thieres_freire@yahoo.com.br, sanddrabastos@yahoo.com.br \\ ${ }^{4}$ Professor, PPGEA, UNIVASF, Juazeiro-BA, mario.miranda@univasf.edu.br \\ ${ }^{(*)}$ Autor para correspondência
}

José Francisco Alves do Carmo ${ }^{1}$, Magna Soelma Beserra de Moura ${ }^{2(*)}$, Thieres George Freire da Silva ${ }^{3}$, Luciana Sandra Bastos de

\section{INFORMAÇÕES}

\section{História do artigo:}

Recebido em 16 de Junho de 2017

Aceito em 10 de agosto de 2017

Termos para indexação:

saldo de radiação

albedo

radiação solar

semiárido
RESUMO

O objetivo desse estudo foi analisar a variação diária e sazonal dos componentes do balanço de radiação em um cultivo de cana-de-açúcar irrigado por gotejamento subsuperficial no Submédio do Vale São Francisco. Para isso, medidas da radiação solar global incidente $(R g)$, radiação refletida, radiação fotossinteticamente ativa incidente (RFA), saldo de radiação $(R n)$ e componentes derivados do balanço de radiação, como o albedo e o coeficiente de transmissividade $(\mathrm{Kt})$ foram obtidos em um experimento com cana-de-açúcar, variedade RB 92 579, em Juazeiro-BA, e analisados no período de novembro de 2010 a outubro de 2011. Em termos diários, as condições de nebulosidade afetaram os componentes do balanço de radiação, com exceção da irradiância de ondas longas pela superfície em condições de plena cobertura do solo, e em menor escala o albedo, que demonstra também dependência do ângulo de inclinação solar. Em escala sazonal, nas fases de desenvolvimento I, II, III e IV, o (Rn) representou, em média, 58, 65, 62 e 59\% da Rg. Os eventos de chuva e de irrigação, a sazonalidade da $\mathrm{Rg}$ e o nível de cobertura do solo influenciaram nos componentes do balanço de radiação e no albedo, que apresentou valor médio igual a $23 \%$.

(c) 2017 SBAgro. Todos os direitos reservados.

\section{Introdução}

A cana-de-açúcar (Saccharum sp.) é uma gramínea de grande importância econômica no Brasil, com os limites de suas fronteiras agrícolas atingindo várias regiões do país, inclusive o Semiárido brasileiro. Logo, a cultura tem experimentado uma diversidade de solos e climas, de maneira que em algumas áreas é possível encontrar condições ideais para sua produção, ao passo que em outras podem ocorrer restrições térmicas e, ou, hídricas moderadas ou excessivas, exigindo ajustes no sistema de produção para viabilização de seu cultivo.

De modo geral, o clima influencia no crescimento, na produtividade e na qualidade da cana-de-açúcar. Sob as condições climáticas do Semiárido brasileiro é possível plantá-la durante todo ano e obter maiores produtividades do que em outras regiões, pois a disponibilidade de energia associada ao uso da irrigação e fertirrigação proporciona melhor desenvolvimento das plantas, maior produção e um produto de melhor qualidade (ANDRADE JÚNIOR et 
al., 2012). Entretanto, essas características estão associadas, dentre outros fatores, a um aumento na produção de biomassa e na evapotranspiração da cultura, que para serem mais bem estudados e compreendidos é essencial se conhecer o balanço de radiação e a interação de cada um dos seus componentes com a cultura.

O saldo de radiação é considerado o principal parâmetro utilizado em métodos de estimativa da transferência de água da superfície para a atmosfera (CAMPBELL; NORMAN, 1998; OLIVEIRA; LEITÃO, 2000; PILAU et al., 2007). A razão entre a radiação solar refletida e a radiação solar incidente é conhecida como albedo (), que é determinante nos valores do balanço de ondas curtas, e por sua vez, no saldo de radiação. Mas, para o crescimento e desenvolvimento da cultura, a mesma se utilizada, sobretudo da radiação fotossinteticamente ativa (). Logo, vários estudos têm relacionado a interceptação da com o índice de área foliar (FERREIRA JÚNIOR et al., 2012; ANDRÉ at al., 2010) e, ou a produção de biomassa (KINIRY et al., 2005).

Em função de sua importância para o setor agrícola e energético nacional é necessário se conhecer como essa cultura interage com o meio para que haja maior eficiência de conversão dos recursos naturais em biomassa, sobretudo nas condições do semiárido brasileiro, onde os eventos de irrigação dependem da captação de água no Rio São Francisco. Assim, objetivou-se analisar a variação diária e sazonal dos componentes do balanço de radiação em um cultivo de cana-de-açúcar irrigado sob as condições climáticas do Submédio do Vale São Francisco.

\section{Material e métodos}

Este estudo foi conduzido em um canavial irrigado pertencente à Empresa Agroindústrias do Vale do São Francisco S.A. - Agrovale (latitude 09²6' S; longitude 4019’ W e altitude de $396 \mathrm{~m}$ ), no município de Juazeiro, Bahia, no Submédio do Vale São Francisco. Segundo a classificação climática de Köppen, esta região apresenta clima do tipo BSwh', caracterizado por clima quente, semiárido, com chuvas de verão e irregulares, temperaturas médias anuais superiores a $18^{\circ} \mathrm{C}$ e ausência de excedente hídrico, o que confere à esta região a necessidade de utilização de irrigação para suprir a necessidade hídrica das culturas.

A variedade de cana-de-açúcar RB 92-579 foi plantada em um Vertissolo, em espaçamento duplo de 1,3 $\mathrm{m}$ por 0,7 $\mathrm{m}$, irrigada por gotejamento subsuperficial, com gotejadores enterrados a 0,20 $\mathrm{m}$ de profundidade.

O estudo foi realizado no ciclo de cana-soca, no período de 19 de novembro de 2010 a 25 de outubro de 2011, totalizando 347 dias após a última colheita (DAC).

Durante este período, os componentes do balanço de radiação foram avaliados considerando quatro estádios de desenvolvimento da cana-de-açúcar (ALLEN et al., 1998).
Estes estádios foram definidos com base em observações biométricas realizadas em campo, de acordo com metodologia descrita em Silva et al. (2011). Dessa forma foram delimitadas as seguintes fases: Fase I - brotação ao estabelecimento, que correspondeu a um período de 21 DAC; Fase II - estabelecimento da planta ao perfilhamento, ocorrido entre 22 e 111 (90 dias); Fase III - referente ao período de máximo crescimento vegetativo, compreendido entre os 112 e 306 (195 dias) e Fase IV - correspondente à maturação fisiológica, que ocorreu entre os 307 e 347 DAC (41 dias).

As irrigações foram realizadas com base na evapotranspiração de referência, esta calculada segundo o método de Penman Monteith parametrizado pela FAO (ALLEN et al., 1998) e no coeficiente da cultura () proposto por Silva et al. (2012). As irrigações foram realizadas diariamente, com exceção nos dias em que houve precipitação, até os 307 DAC, quando então, a irrigação foi suspensa visando proporcionar a maturação dos colmos e, por conseguinte, aumento da concentração de sacarose nos colmos.

A lâmina de água aplicada por irrigação foi da ordem de $1496,8 \mathrm{~mm}$, enquanto o total precipitado foi $189,8 \mathrm{~mm}$, totalizando $1686,6 \mathrm{~mm}$ de água. Os principais eventos de chuva ocorreram em dezembro de 2010 e em fevereiro de 2011, compreendendo as fases de desenvolvimento I e II do ciclo de cultivo.

A Figura 1 mostra a variação de água no solo ao longo do ciclo de cultivo, bem como o conteúdo de água no solo.

Os componentes do balanço de radiação foram medidos por meio de um saldo radiômetro (CNR1, Kipp Zonen INC, NY, USA), instalado a 8,0 $\mathrm{m}$ da superfície do solo. A quantificação do nível de cobertura do solo, índice de área foliar e fração da radiação fotossinteticamente ativa interceptada foram medidos por dois tipos de sensores de radiação quantum, sendo um pontual (LI-190, Campbell Scientific INC, Logan, Utah, USA) instalado no topo da torre e dois sensores quantum lineares (modelo LI-191, Campbell Scientific INC, Logan, Utah, USA) posicionados na superfície do solo (abaixo do dossel da cultura). Medidas de temperatura e de umidade relativa do ar, velocidade do vento, precipitação e temperatura do solo também foram registrados. A aquisição e armazenamento dos dados foram feita por meio de um micrologger (CR23X, Campbell Scientific INC, Logan, Utah, USA), programado para realizar leituras a cada minuto e registrar a média dos dados a cada 30 minutos.

A representação do saldo de radiação $(R n)$ é dada pela expressão:

$$
R n=B O C+B O L
$$

em que é o saldo de radiação, é o balanço de radiação de ondas curtas e BOL é o balanço de radiação de ondas longas. 


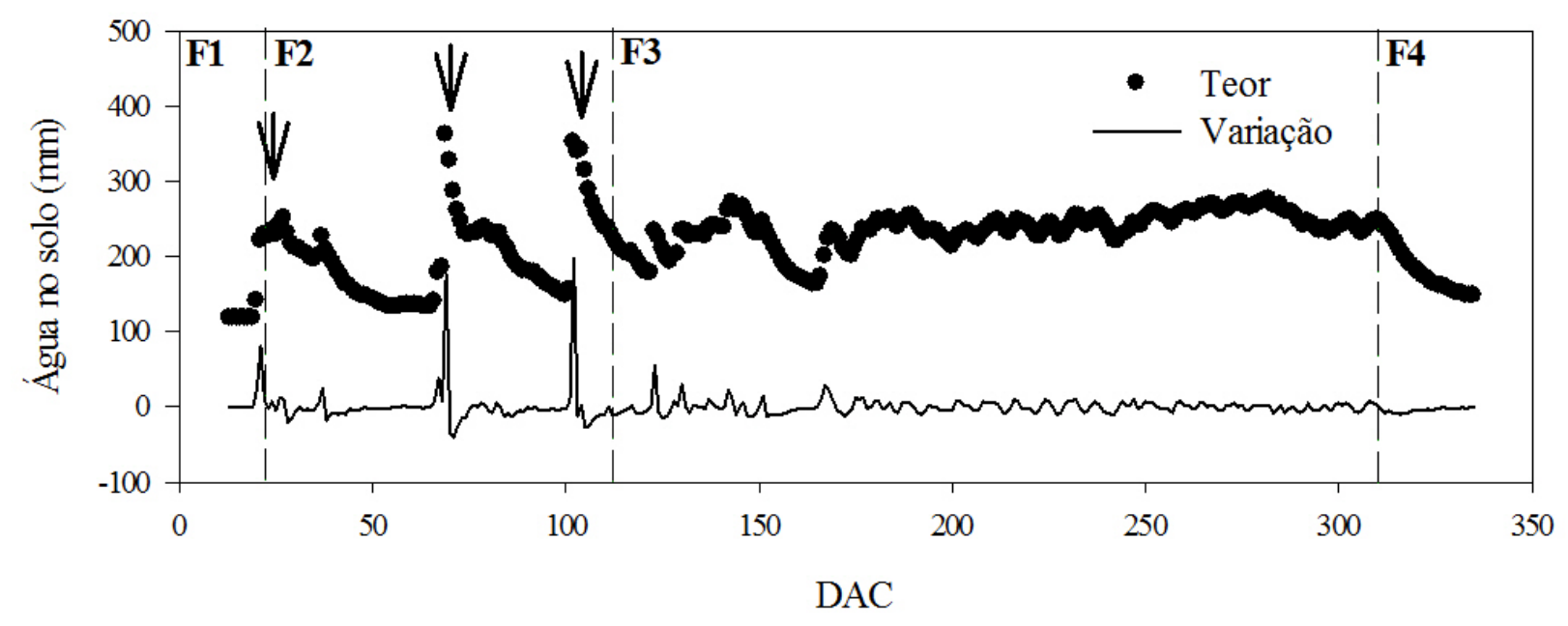

Figura 1. Totais diários da lâmina de irrigação e precipitação pluviométrica durante o ciclo de cana-soca da variedade RB 92579 irrigada por gotejamento subsuperficial no Submédio do Vale São Francisco, Juazeiro - BA.

O balanço de radiação de ondas curtas, obtido pela diferença entre a radiação solar de ondas curtas incidentes sobre a superfície (radiação solar global) e a radiação de ondas curtas refletidas pela superfície do sistema, foi calculado pela seguinte equação:

$$
B O C=Q g-r Q g
$$

em que é a radiação solar global incidente, em e é a radiação solar de ondas curtas refletida pela superfície, em.

A depende da capacidade de reflexão de parte da radiação de ondas curtas pela superfície, esta conhecida como albedo $(r)$ ou coeficiente de reflexão, que foi obtida pela razão entre a radiação refletida $(r Q g)$ e a radiação solar global $(Q g)$ :

$$
r=\frac{r Q g}{Q g} \times 100
$$

em que r é dado em porcentagem (\%).

O balanço de radiação de ondas longas (BOL) foi obtido pela diferença entre o fluxo de radiação de ondas longas da atmosfera que é emitido para a superfície e o fluxo de radiação de ondas longas emitido pela superfície em direção à atmosfera, dado por:

$$
B O L=Q a-Q s
$$

em que $Q a$ é a radiação de ondas longas incidente sobre a superfície, e Qs é a radiação de ondas longas refletida pela superfície.

A unidade utilizada para todos os fluxos de radiação foi em W m ${ }^{-2}$ quando se referirem a medidas médias instantâneas a cada 30 min e $\mathrm{MJ} \mathrm{m}^{-2}$, para os totais diários.

Por sua vez, convencionou-se que os fluxos de radiação em direção à superfície são positivos, enquanto os que são emitidos em direção à atmosfera, negativos.

Além dos componentes do balanço de radiação também foi obtida a transmissividade atmosférica $(K t)$ com base na razão entre os fluxos integrados da radiação solar global incidente à superfície $(Q g)$ e no topo da atmosfera $(Q o)$, conforme equação a seguir:

$$
K t=\frac{Q g}{Q o}
$$

em que Kt é a transmissividade atmosférica (adimensional), $Q g$ é radiação solar incidente à superfície e Qo é a irradiância no topo da atmosfera (Vianello e Alves,1991), com base na latitude local, declinação solar e ângulo horário.

Segundo Escobedo et al. (2009) foram usados os dados de Kt para identificação das condições de cobertura de céu, adotando-se: $\mathrm{Kt}<0,35$ para céu nublado; 0,35 $\leq \mathrm{Kt}>$ 0,55 , para céu parcialmente nublado; $0,55 \leq \mathrm{Kt} \leq 0,65$, para a condição de céu parcialmente aberto; e Kt >0,65 para céu aberto ou ensolarado.

A variação dos componentes do balanço de radiação foi analisada nas fases de desenvolvimento da cana-de-açúcar (Fases I, II, III e IV), sempre ao longo de um dia de céu aberto e um dia de céu nublado ou parcialmente nublado, com exceção da fase III, para a qual foram observados dois dias ensolarados e dois dias de céu nublado (ou parcialmente nublados), devido sua maior duração (09 de março a 20 de setembro de 2011). Adicionalmente, foi feita a análise dos parâmetros ao longo do ciclo de cultivo em termos de valores médios diários. Assim, a determinação do saldo de ra- 
diação foi obtida com base na obtenção detalhada de cada componente, como segue:

$$
R n=Q g+r Q g+Q a+Q s
$$

Com base nos dados medidos de radiação fotossinteticamente ativa (RFA) foi obtido o nível de cobertura do solo (NCS) ou a fração da radiação fotossinteticamente ativa interceptada (fRFAi) pelo dossel, utilizando-se a equação (GOWER et al, 1999):

$$
f R F A_{i}=1-\frac{R F A_{b}}{R F A_{t}}
$$

em que RFAt é a radiação fotossinteticamente ativa incidente no topo do dossel e RFAb corresponde a radiação fotossinteticamente ativa que alcança a superfície do solo. Os dados medidos da radiação fotossinteticamente ativa a cada 30 minutos, em $\mu$ molm ${ }^{-2} \mathrm{~s}^{-1}$, foram convertidos em totais diários $\left(\mathrm{MJ} \mathrm{m}^{-2}\right)$ e utilizados para o cálculo diário de sua fração interceptada (fRFAi), bem como do seu valor médio para o período de estudo.

Ao longo do tempo também foi determinado o IAF, por meio dos procedimentos citados por Silva et al. (2012). Nesta etapa seis plantas foram amostradas e a área das fo- lhas foram medidas mediante um integrador de área foliar (LI-3000, LI-COR, Inc. Linoln, Nebraka, USA). Os dados de IAF foram relacionados com o número de dias após a colheita (DCA), a fim de se ajustar um modelo matemático para estimava dos seus valores ao longo do ciclo.

\section{Resultados e discussão}

Na Figura 2 são apresentadas as marchas diárias da radiação solar ocorrida no topo da atmosfera (Qo) e na superfície vegetada $(\mathrm{Qg})$, e a transmissividade atmosférica ou coeficiente de claridade (Kt) (Figura 4). Os extremos de Qo ocorreu entre o dia 23 de junho/2011 (25,75 MJ m²) e 25 de dezembro/2011 (43, $35 \mathrm{MJ} \mathrm{m}^{-2}$ ) (Figura 2A).

$\mathrm{O}$ valor diário de Kt (Figura $2 \mathrm{~B}$ ) seguiu as variações correspondentes à $\mathrm{Qg}$, apresentando variação entre 23,17 e 83,03\%, com média de 59,41\%.

Dos 323 dias avaliados, apenas 3,1\% foram caracterizados como dias de céu nublado, enquanto 33,4\% (108 dias) corresponderam a dias de céu aberto, com Kt maior do que 0,$65 ; 32,8 \%$ equivaleram a dias parcialmente nublados e $30,7 \%$ de dias parcialmente abertos. Portanto, $64,1 \%$ do total de dias analisados, foram considerados dias de céu parcialmente aberto e aberto.

Assim, de acordo com os dados de Kt foram selecionados os dias ensolarados (S), que constituíram os 13 DAC (Fase I), 35 DAC (Fase II), 139 e 256 DAC (Fase III), 310 DAC
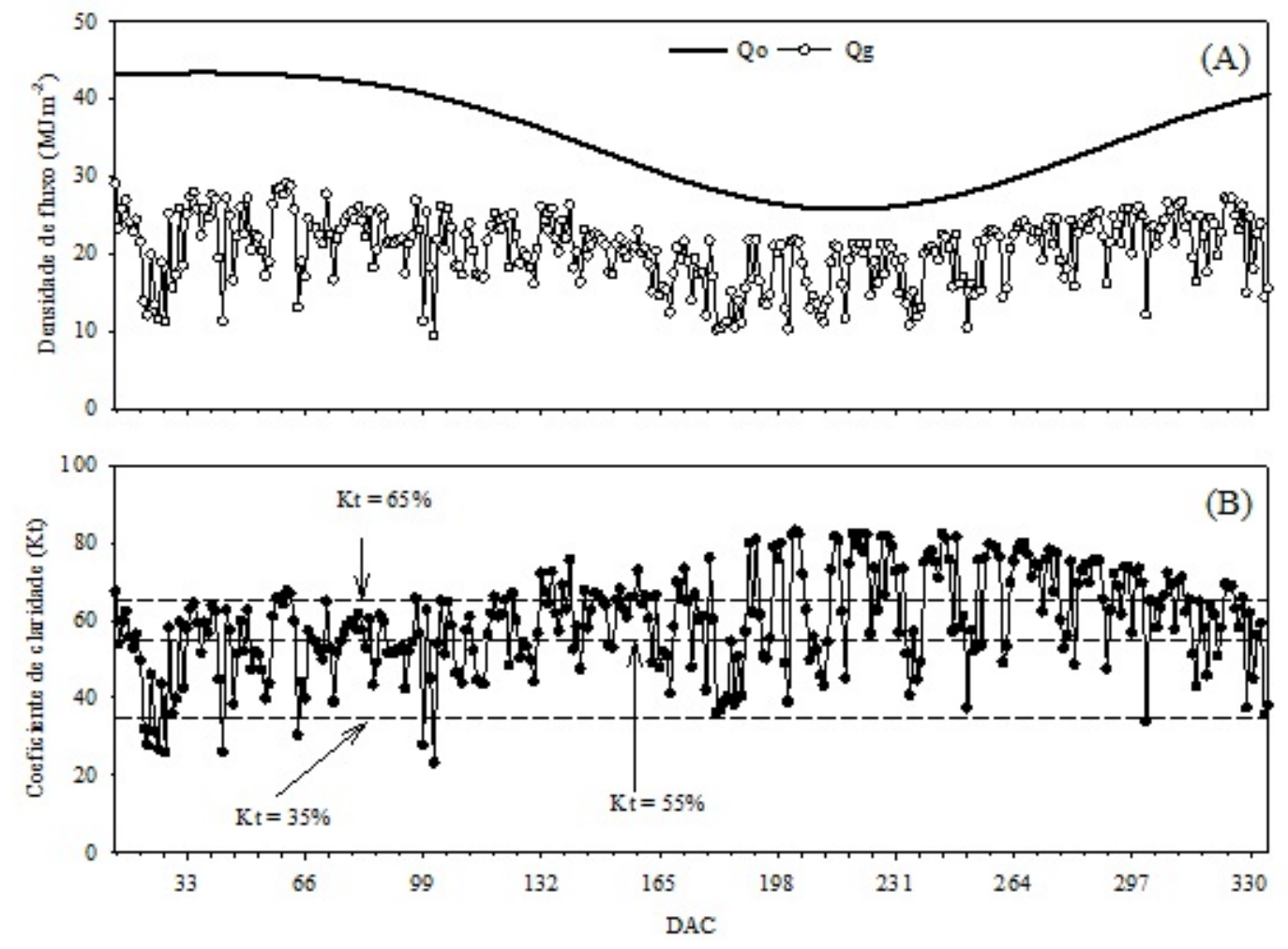

Figura 2. (A) Radiação solar diária no topo da atmosfera (Qo) e à superfície (Qg) e (B) coeficiente de claridade (Kt) na área de cultivo da cana-de-açúcar variedade RB 92-579 irrigada por gotejamento subsuperficial no Submédio do Vale São Francisco, Juazeiro-BA. 

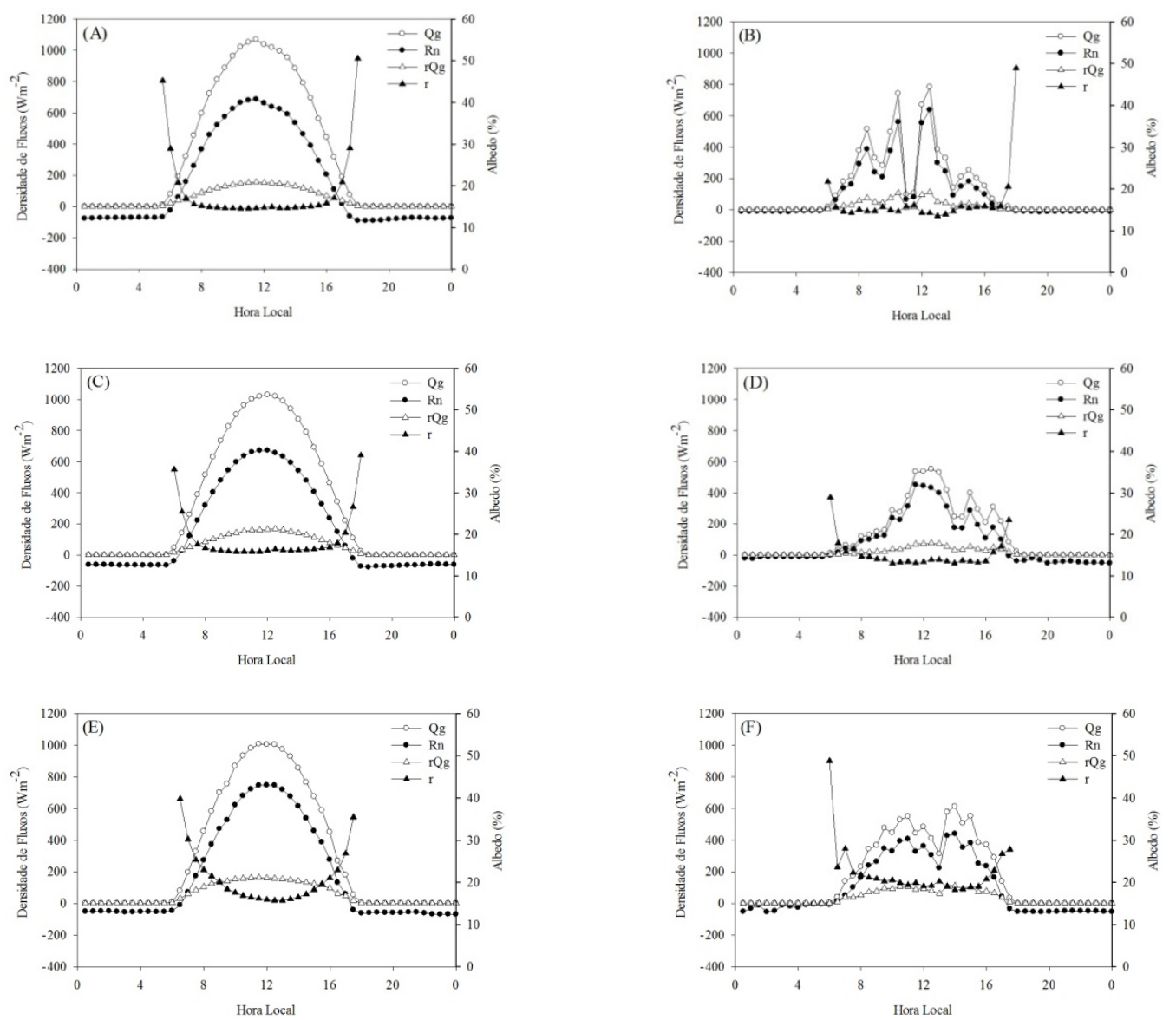

Figura 3. Variação diurna da radiação global $(\mathrm{Qg})$, radiação refletida (rQg), saldo de radiação (Rn) e albedo (r) para dias de céu claro e nublados, representativos das fases de crescimento da cana-de-açúcar, Juazeiro-BA. Obs.: dias ensolarados (S) - 13 DAC (A, Fase I), 35 DAC (C, Fase II), 139 e 256 DAC (E e G, Fase III), 310 DAC (I, Fase IV); e dias nublados ou parcialmente nublados (N) corresponderam aos 25 DAC (B, Fase I), 43 DAC (D, Fase II), 162 e 271 DAC (F e H, Fase III) e 328 DAC (J, Fase IV).

(Fase IV), respectivamente com Kt iguais a 72\%, 69\%, 75\%, $80 \%$ e $71 \%$; e nublados ou parcialmente nublados $(\mathrm{N})$ corresponderam aos 25 DAC (Fase I), 43 DAC (Fase II), $162 \mathrm{e}$ 271 DAC (Fase III) e 328 DAC (Fase IV). Esses dias foram utilizados nas análises diurnas e diárias dos componentes do balanço de radiação.

Na Figura 3 está a variação diurna da radiação solar incidente $(\mathrm{Qg})$, radiação refletida $(\mathrm{rQg})$, saldo de radiação (Rn) e albedo (r) de dias representativos das quatro fases de desenvolvimento da cana-de-açúcar, selecionados com base no Kt (Figura 2B).

As curvas de Qg mostraram comportamento semelhante nos dias ensolarados, com valores máximos na ordem de 1070; 1030; 1006; 888 e $1022 \mathrm{Wm}^{-2}$ atingidos entre 11h30min e 11h47min nos dias 13, 35, 139, 256 e 310 DAC, respectivamente (Figura 3 ). Estes instantes coincidem com o meio dia solar e correspondem aos momentos em que os raios solares incidem mais perpendicularmente sobre a superfície.

Embora o dia 256 DAC (01/08/2011) tenha sido considerado de sol pleno, (Figura 3G), destacou-se como o dia com o menor valor de Qg por se tratar de um dia de inverno (01/08/2011), período no qual o sol encontrava-se declinado mais para o norte, mais distante da terra e com menor ângulo de incidência, proporcionou uma menor incidência de radiação sobre a cultura.

Percebe-se ainda na Figura 3 que em todos os dias ensolarados, os menores valores de Qg foram constatados na parte inicial e final do dia devido ao ângulo de inclinação dos raios solares terem que atravessar uma camada atmosférica mais espessa, ocorrendo assim uma interação maior da radiação solar com os aerossóis e partículas presentes na atmosfera antes de atingir a superfície. Na mesma ordem, as curvas deste parâmetro obtidas para dias nublados, bem como para Rn, rQg e albedo (Figuras 3B, 3D, 3F, $3 \mathrm{H}$ e 3J), mostraram acentuada variação ao longo do dia devido à presença frequente da nebulosidade.

O albedo apresentou-se crescente ao longo dos dias de sol pleno observados, com menores valores próximos ao meio-dia de 0,$15 ; 0,17 ; 0,18 ; 0,19$ e 0,22, respectivamente para os 13, 35, 139, 256 e 310 DAC. Esse comportamento diferente do obtido para Qg indica que o albedo é mais bem 
DAC

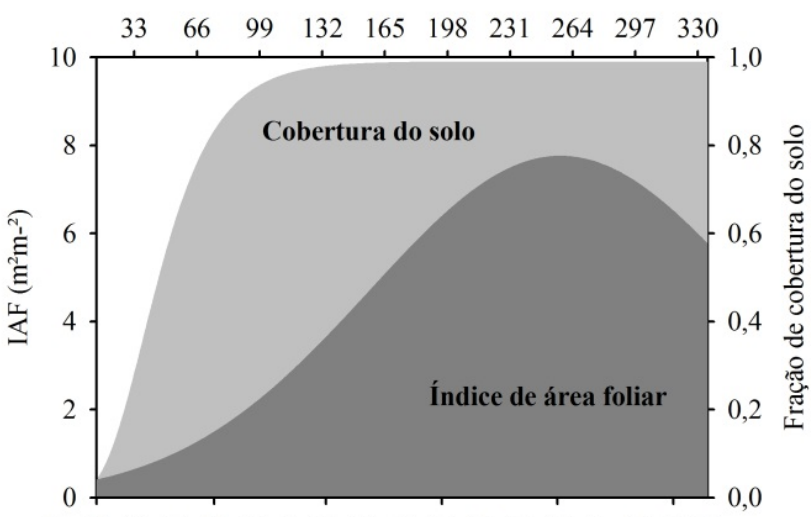

01-12-10 01-02-11 01-04-11 01-06-11 01-08-11 01-10-11

Data

$\mathrm{IAF}=-1,98+9,67 \exp \left\{[((\mathrm{DAC}-221,34) / 120,42)]^{\wedge} 2\right\}$ $\mathrm{R}^{2}=0,96$

Figura 4. Fração de cobertura do solo e índice de área foliar (IAF) da cana-de-açúcar variedade RB 92579 irrigada por gotejamento subsuperficial, durante o ciclo de cana-soca, no Submédio do Vale São Francisco, Juazeiro-BA.

explicado pelo desenvolvimento da cultura, que vai paulatinamente proporcionando maior cobertura do solo ao longo do ciclo (Figura 4), do que pela própria sazonalidade da Qg.

A Tabela 1 sumariza os valores diários para a radiação de ondas longas advinda da atmosfera (Qa), radiação de ondas longas emitida pela superfície (Qs), balanço de radiação de ondas curtas (BOC), balanço de radiação de ondas longas (BOL) e a relação de Rn/Qg. Percebe-se que o menor valor médio de rQg contrasta com a maior incidência de Qg da Fase I quando comparado com as demais. Acontece que esta fase compreende o período de reduzida cobertura do solo (cerca de $2 \%$ ), como pode ser constatado na Figura 4, o que sugere uma maior absorção de radiação incidente pelo sistema confirmada pelo maior valor de Qs.
Ainda no que se referem aos valores médios diários foram observadas nas duas primeiras fases, diferenças expressivas de $\mathrm{r}$ entre um dia ensolarado e um dia nublado em (4,0\%). No entanto, comparando-se as fases (Tabela 1 ), em ambos os dias observados para as Fases I e II o albedo constatado foi menor que o observado para as Fases III e IV. Isso reforça o que foi constatado para rQg e indica que houve uma maior absorção da radiação incidente pelo sistema solo-planta nos dois primeiros casos.

Em termos de balanço de ondas longas (BOL), a Tabela 1 mostra que a emitância atmosférica apresentou valores menores do que a emitância terrestre, tanto nos dias ensolarados quanto nos nublados, para as quatro fases. Porém, verifica-se que a diferença entre Qs e Qa foi maior nos dias com maior incidência de radiação global e em decorrência disso o BOL apresentou valores muito mais negativos nos dias ensolarados do que nos dias nublados. Como consequência, nos dias ensolarados a amplitude entre $\mathrm{Qg}$ e Rn foi maior do que nos dias nublados.

Analisando os componentes do balanço de radiação longo do ciclo de cultivo, (Figura 5), observa-se que a radiação solar global (Qg) foi mais elevada no início, apresen-

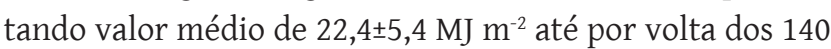
DAC, (07 de abril de 2011). A partir desta data, os valores de Qg começaram a decrescer até por volta dos 230 DAC (07 de julho de 2011), com valores abaixo de $20 \mathrm{MJ} \mathrm{m}^{-2}$.

Em seguida, observou-se a elevação gradativa da densidade de fluxo de Qg, a qual somete se estabiliza ao período final do ciclo de cultivo, com valores semelhantes aos constatados ao início, comportamento que segue o padrão sazonal de radiação solar incidente na região. Em termos de ciclo da cultura, esse parâmetro mostrou comportamento inverso ao que foi observado por Silva et al. (2011), em estudo sobre balanço de radiação e energia em um ciclo de cana-de-açúcar sob as condições de semiárido.

Tabela 1. Valores diários dos componentes do balanço de radiação $\left(\mathrm{MJ} \mathrm{m}^{-2}\right)$ em um dia ensolarado (S) e um dia nublado (N) em diferentes estádios de desenvolvimento da cana-de-açúcar irrigada, Juazeiro-BA.

\begin{tabular}{|c|c|c|c|c|c|c|c|c|c|c|c|c|}
\hline & & DAC & Qg* & rQg* & $\mathbf{r * *}$ & Qa* & BOL* & BOC* & Rn* & Rn/Qg & Qo* & $\mathbf{K t}^{* * *}$ \\
\hline$\overline{\text { Fase }}$ & $\mathrm{S}$ & 13 & 29,9 & 4,4 & 0,15 & 32,2 & $-10,9$ & 24,7 & 13,8 & 47,4 & 40,7 & 0,72 \\
\hline I & $\mathrm{N}$ & 22 & 12,1 & 1,8 & 0,15 & 37,2 & $-1,7$ & 10,3 & 8,5 & 70,8 & 40,6 & 0,30 \\
\hline Fase & S & 35 & 27,9 & 4,6 & 0,17 & 32,6 & $-9,2$ & 23,3 & 14,0 & 50,3 & 40,6 & 0,69 \\
\hline II & $\mathrm{N}$ & 43 & 11,3 & 1,6 & 0,14 & 35,9 & $-2,8$ & 9,7 & 6,9 & 61,2 & 40,6 & 0,28 \\
\hline Fase & S & 139 & 26,4 & 4,8 & 0,18 & 32,7 & $-6,2$ & 21,5 & 15,4 & 58,2 & 35,1 & 0,75 \\
\hline III & $\mathrm{N}$ & 162 & 15,1 & 3,0 & 0,20 & 34,8 & $-3,4$ & 12,1 & 8,7 & 57,5 & 31,9 & 0,47 \\
\hline Fase & S & 256 & 22,9 & 4,4 & 0,19 & 31,3 & $-6,4$ & 18,4 & 12,1 & 52,8 & 28,5 & 0,80 \\
\hline III & $\mathrm{N}$ & 271 & 19,2 & 4,0 & 0,21 & 33,6 & $-4,2$ & 15,3 & 11,1 & 57,7 & 30,8 & 0,63 \\
\hline Fase & S & 310 & 26,7 & 5,8 & 0,22 & 31,3 & $-7,8$ & 20,9 & 13,2 & 49,2 & 37,5 & 0,71 \\
\hline IV & $\mathrm{N}$ & 328 & 14,9 & 3,4 & 0,23 & 35,1 & $-4,1$ & 11,5 & 7,4 & 49,3 & 39,9 & 0,37 \\
\hline
\end{tabular}

*Valores dados em MJ m²; **Adimensional; Qg=Radiação solar global incidente; rQg=radiação solar refletida; r=albedo; Qa=radiação de ondas longas incidente; Qs=radiação de ondas longas refletida; BOC=Saldo de radiação de ondas curtas; BOL=Saldo de radiação de ondas longas; Rn=Saldo total de radiação; Qo=Irradiância solar no topo da atmosfera; 

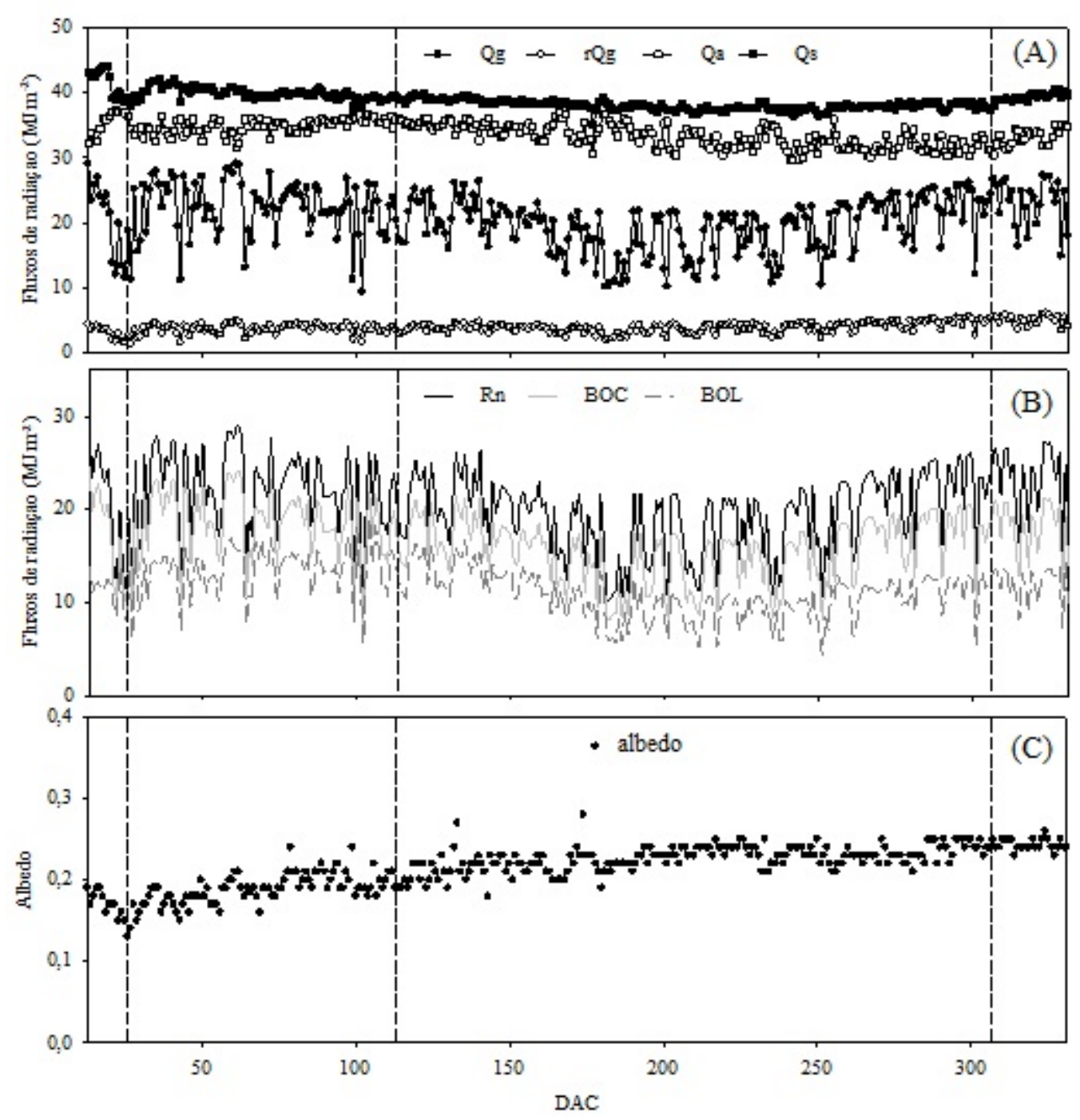

Figura 5. Totais diários dos componentes do balanço de radiação em função do número de dias após a colheita (DAC) da cana-de-açúcar variedade RB 92579 irrigada por gotejamento subsuperficial, Juazeiro-BA. *(a) Radiação solar global (Qg), radiação de ondas curtas refletida (rQg), radiação de ondas longas emitida pela atmosfera (Qa) e radiação de ondas longas emitida pela superfície (Qs); (b) Saldo de radiação (Rn), balanço de radiação de ondas curtas (BOC) e balanço de radiação de ondas longas (BOL); e (c) Albedo ou coeficiente de reflexão da radiação de ondas longas.

No entanto, a época de início do cultivo do referido autor, compreendeu o período de junho de 2007 a junho de 2008, logo, os valores estão de acordo com a Qg com as efemérides astronômicas causadas pela distância relativa terra-sol (PEREIRA, 2002).

As condições de pouco sombreamento do solo até os 44 DAC (nível de cobertura do solo $<50 \%$ ) proporcionaram maior absorção da radiação incidente pelo sistema, o que pode ser constatado na Figura 4A, na qual, durante esse período observaram-se baixos valores médios de $\operatorname{rQg}(3,2 \pm 0,8$ MJ $\mathrm{m}^{-2}$ ).

A partir daí até os 80 DAC os valores médios de rQg au-

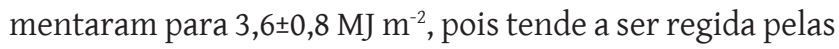
flutuações de Qg, em decorrência do aumento do índice de cobertura do solo (Figura 4), condição esta que se mantém até o fim do ciclo de cultivo da cana. No entanto, por volta dos 180 DAC, observou-se uma redução acentuada nos valores de rQg, em virtude do tombamento característico da variedade, evento este que provocou distúrbios no arranjo do aparato fotossintético da cana, expondo tanto os colmos da planta, quanto parte da superfície do solo, o que pode condicionar o aumento da absorção de radiação e, consequentemente, redução dos valores da rQg. Resultados semelhantes foram observados por Silva et al. (2011) aos 238 DAC em estudo de variação do balanço de radiação e de energia da cana-de-açúcar irrigada por sulcos sob condições climáticas semelhantes.

Quando se analisou a variação dos valores médios diários relativos à radiação de ondas longas emitidas pela superfície, constatou-se que eles foram mais elevados do que a emitância atmosférica (Figura 5A). No início do ciclo de cultivo os valores de Qs apresentaram-se bem mais elevados do que os de Qa, o que justifica a obtenção de valores mais negativos constatados para o BOL. A partir de então, 
Tabela 2. Valores médios, em MJ m² (albedo em \%) dos componentes do balanço de radiação para as quatro fases de desenvolvimento da cana-de-açúcar irrigada por gotejamento subsuperficial no Submédio do Vale São Francisco, Juazeiro-BA.

\begin{tabular}{ccccccccccc}
\hline & $\begin{array}{c}\text { Duração } \\
\text { (dias) }\end{array}$ & Qg & rQg & r & Qa & Qs & Rn & BOC & BOL & Rn/Qg \\
\hline Fase I & 22 & 22,4 & 3,4 & $19 \%$ & 34,8 & 42,3 & 13,8 & 18,9 & $-7,5$ & 0,58 \\
Fase II & 90 & 22,2 & 3,6 & $21 \%$ & 34,9 & 39,9 & 15,4 & 18,5 & $-5,0$ & 0,65 \\
Fase III & 195 & 19,4 & 3,9 & $25 \%$ & 33,2 & 37,9 & 13,0 & 15,5 & $-4,9$ & 0,62 \\
Fase IV & 31 & 22,5 & 4,9 & $26 \%$ & 33,7 & 39,4 & 14,4 & 17,6 & $-5,7$ & 0,59 \\
\hline
\end{tabular}

a diferença entre Qa e Qs tendeu a diminuir até 140 DAC, proporcionando pequenas flutuações dos valores de BOL até o final do ciclo de cultivo da cana.

Ferreira Júnior et al. (2012), em estudo realizado com cana-de-açúcar em Rio Largo, AL, observaram que os maiores valores de índice de área foliar (IAF) da variedade $\mathrm{RB}$ 92-579 no início do ciclo coincidiram com altos fluxos de radiação solar, sendo que esta variedade destacou-se por apresentar maior interceptação de RFA acumulada durante o ciclo de cultivo, com IAF máximo igual a $3,84 \mathrm{~m}^{2} \mathrm{~m}^{-2}$. Estes autores informam que a média diária da radiação solar incidente no cultivo foi Ada ordem de 20,9 MJ mªté os 70 DAC, com interceptação de RFA equivalente a 1,9MJ $\mathrm{m}^{-2}$. Nesse mesmo estudo, entre os 71 e $193 \mathrm{DAC}$, a radiação solar incidente média de apenas $14,9 \mathrm{MJ} \mathrm{m}^{-2}$, o que pode ter limitado o crescimento das plantas. Por outro lado, André et al. (2010) realizaram estudo concernente aos aspectos energéticos do desenvolvimento da cana-de-açúcar, em Campo dos Goytacazes, RJ, observaram que na fase de desenvolvimento dos colmos, a irradiância solar global foi de 20,36 $\mathrm{MJ} \mathrm{m}^{-2}$, quando acultura apresentava um índice de área foliar entre 7,0 e $8,0 \mathrm{~m}^{2} \mathrm{~m}^{-2} \mathrm{e}$ as plantas apresentavam altura média de $3,65 \mathrm{~m}$.

O saldo de radiação (Figura 5B) variou de acordo com a sazonalidade apresentada pela radiação global (Figura 5A), com exceção para o período inicial, no qual foi regido pelas mudanças nos componentes proporcionadas pelo intenso crescimento da cultura. No início do ciclo de desenvolvimento da cultura (Fase I), com Rn representando 58\% de $\mathrm{Qg}$, os valores do BOC apresentaram-se mais elevados $\left(19,0 \pm 4,6 \mathrm{MJ} \mathrm{m}^{-2} \mathrm{dia}^{-1}\right)$, como resultado da maior incidência de $Q g$, quando então tendeu a decrescer até por volta os 240 DAC (Fase III) (Figura 5B). Os menores valores constatados deste parâmetro, associados à relativa elevação do BOL resultaram em pequenos valores de Rn (9,5 $52,2 \mathrm{MJ}$ m${ }^{-2}$ dia $^{-1}$ ) (Figura 5B).

$\mathrm{Na}$ Fase II, que representa a fase de perfilhamento e estabelecimento da cana-de-açúcar, o saldo de radiação representou $65 \%$ da radiação global, indicando maior demanda de energia pelo sistema. As Fases I, III e IV apresentaram valores na relação Rn/Qg da ordem de 58\%, 62\% e
59\%, respectivamente, (Tabela 2). Silva et al. (2011), comparando a relação Rn/Qg em cana-de-açúcar sob condições irrigadas, obteve valor médio de 59,5\%; enquanto Teixeira et al. (2008), obtiveram valores de 51 e $50 \%$ em cultivos irrigados de mangueira e uva de vinho; que também são cultivos importantes para a região do Submédio do Vale São Francisco.

A maior absorção de energia pelo sistema foi constatada no início do ciclo de cultivo da cana em decorrência da obtenção dos menores coeficientes de reflexão (Figura 8C). Observou-se que os valores deste parâmetro evoluíram de acordo com o desenvolvimento da cultura, tendo alcançado os menores valores até os $60 \mathrm{DAC}$, quando então tenderam a elevar-se date os 310 DAP. Nesse momento a irrigação foi suspensa, caracterizando início da fase de maturação fisiológica, na qual a cultura é submetida a estresse hídrico, visando aumento da concentração de sacarose nos colmos, condição esta que proporcionou um declínio considerável dos valores do albedo (Figura 8C).

Os valores médios constatados para as Fases I, II, III e VI foram $19 \pm 1,9 \%, 21 \pm 4,9 \%, 25 \pm 3,1 \%$ e $26 \pm 4,7 \%$, respectivamente, cujo valor médio para o ciclo foi de $23 \pm 4,3 \%$. Valores semelhantes foram constatados por Silva et al. (2011) estudando a variação do balanço de radiação em cana-de-açúcar irrigada por sulcos, em Juazeiro, BA, quando observaram entre os 50 e 300 DAC que a radiação total incidente variou entre 20 e $26 \mathrm{MJ} \mathrm{m}^{-2}$, enquanto o albedo apresentou variação de $15 \%$ aos $50 \mathrm{DAC}$ à $27 \%$ aos $230 \mathrm{DAC}$, com albedo médio igual a $23 \%$ e IAF máximo igual a $5,5 \mathrm{~m}^{2} \mathrm{~m}^{-2}$.

Esses valores foram semelhantes aos observados por Cabral et al. (2012), que obtiveram albedo para a cana-de-açúcar cultivada em São Paulo variando entre 0,15 (15\%) e 0,23 (23\%), do início ao final do ciclo produtivo, com índice de área foliar máximo da ordem de 5,0 $\mathrm{m}^{2} \mathrm{~m}^{-2}$.

Entretanto, um pouco diferente daqueles constatados por André et al. (2010), que apesar de terem apresentados valores também crescentes do albedo com o aumento do IAF da cultura, seu valor médio foi de $0,24(24 \%)$ para o estádio de perfilhamento, 0,27 (27\%) para estádio inicial de desenvolvimento de colmos, 0,30 (30\%) para o desenvolvimento de colmos e 0,31 (31\%) para maturação, com valor 
médio do albedo para todo o ciclo da cultura igual a 0,28 (28\%); Silva et al. (2011) observou valores oscilando entre 15 e $27 \%$, com valor médio de $23 \%$ para o ciclo.

\section{Conclusões}

As condições de nebulosidade afetaram de maneira marcante os componentes do balanço de radiação, com exceção da emitância de radiação de ondas longas pela superfície em condições de plena cobertura do solo, e em menor escala, o albedo, que demonstrou, também, dependência do ângulo de inclinação solar.

Os eventos de chuva e de irrigação, a sazonalidade da radiação solar global e o nível de cobertura do solo influenciaram de modo significante nos componentes do balanço de radiação e no albedo da cana-de-açúcar irrigada por gotejamento subsuperficial.

\section{Agradecimentos}

À AGROVALE pela concessão da área experimental de cana-de-açúcar, à Embrapa Semiárido pela infraestrutura logística e à CAPES.

\section{Referências}

ALLEN, R. G. et al. Crop evapotranspiration: Guidelines for computing crop water requirements. Rome: FAO, 1998. 300 p. (FAO - Irrigation and Drainage Paper, 56).

ANDRADE JÚNIOR, A. S. et al. Níveis de água, nitrogênio e potássio por gotejamento subsuperficial em cana de açúcar. Pesquisa Agropecuária Brasileira, Brasília, v.47, n.1, p.76-84, 2012.

ANDRÉ, R. G. B. et al. Aspectos energéticos do desenvolvimento da cana de açúcar. Parte 1: balanço de radiação e parâmetros derivados. Revista
Brasileira de Meteorologia, São Paulo, v. 25, n. 3, p. 375-382, 2010.

CABRAL, O. M. R. et al. Water use in a sugarcane plantation. Global Change Biology Bioenergy, v. 4, p. 555-565, 2012.

CAMPBELL, G. S.; NORMAN, J. M. An introduction to environmental biophysics. New York: Springer-Verlag, 1998. 286 p.

ESCOBEDO, J. F. et al. Modeling hourly and daily fractions of UV, PAR and NIR to global solar radiation under various sky conditions at Botucatu, Brazil. Applied Energy, v. 86, p. 299-309, 2009.

FERREIRA JÚNIOR, R. A. et al. Crescimento e fotossíntese de cana de açúcar em função de variáveis biométricas e meteorológicas. Revista Brasileira de Engenharia Agrícola e Ambiental, Campina Grande, v. 16, n. 11, p. 1229-1236, 2012.

KINIRY, J. R. et al.. Peanut leaf area index, light interception, radiation use efficiency, and harvest index at three sites in Texas. Field Crops Research, Amsterdam, v. 91, p. 297-306, 2005.

OLIVEIRA, G. M.; LEITÃO, M. M. V. B. R. Estimativas de evapotranspiração e as consequências devido aos erros na determinação de saldo de radiação e efeitos advectivos. Revista Brasileira de Engenharia Agrícola e Ambiental, Campina Grande, v. 4, n. 3, p. 343-347, 2000.

PEREIRA, A. R.; ANGELOCCI, L. R.; SENTELHAS, P. C. Agrometeorologia: fundamentos e aplicações práticas. Guaíba-RS: Agropecuária, 2002, 478 p.

PILAU, G. P.; ANGELOCCI, L. R.; SCARPARI FILHO, J. A. Balanço de radiação de uma laranjeira em pomar e sua relação com radiação solar global e com saldo de radiação de gramado. Revista Brasileira de Agrometeorologia, Santa Maria, v. 15, n. 3, p. 257-266, 2007.

SILVA, T. G. F. et al. Variação do Balanço de Radiação e de Energia da Cana de açúcar Irrigada no Semiárido Brasileiro. Revista Brasileira de Engenharia Agrícola e Ambiental, Campina Grande, v. 15, n. 2, p. 139-147, 2011.

SILVA, T. G. F. et al. Biometria da parte aérea da cana soca irrigada no Submédio do Vale do São Francisco. Revista Ciência Agronômica, Fortaleza, v. 43, p. 500-509, 2012.

TEIXEIRA, A. H. de C. et al. Analysis of energy fluxes and vegetationatmosphere parameters in irrigated and natural ecosystems of semi-arid Brazil. Journal of Hydrology, Amsterdam, v. 362, p. 110-127, 2008.

VIANELLO, R. L., ALVES, A. R. Meteorologia básica e aplicações. Viçosa: Imprensa Universitária, UFV, 1991. 449 p.

REFERENCIAÇÃO

CARMO, J. F. A. do; MOURA, M. S. B. de; SILVA, T. G. F. da; SOUZA, L. S. B. de; LEITÃo, M. de M. V. B. R. Balanço de radiação da cana-de-açúcar irrigada por gotejamento subsuperficial no submédio do vale São Francisco. Agrometeoros, Passo Fundo, v.25, n.1, p.91-100, 2017.

Declaração: os trabalhos estão sendo publicados nesse número de AGROMETEOROS (v.25, n.1, ago 2017) conforme foram aceitos pelo XX Congresso Brasileiro de Agrometeorologia, realizado de 14 a 18 de agosto de 2017, em Juazeiro, BA e Petrolina, PE, sem revisão editorial adicional da revista. 


\section{Radiation balance of the sugarcane irrigated by subsufarce drip in submedio of the São Francisco Valley}

José Francisco Alves do Carmo ${ }^{1}$, Magna Soelma Beserra de Moura ${ }^{2(*)}$, Thieres George Freire da Silva ${ }^{3}$, Luciana Sandra Bastos de Souza $^{3}$, Mario de Miranda Vilas Boas Ramos Leitao ${ }^{4}$

${ }^{1}$ Mestre, CPGEA, UNIVASF, Juazeiro-BA, j.francarmo@gmail.com

${ }^{2}$ Pesquisadora, Embrapa Semiárido, Petrolina-PE, magnamoura@embrapa.br

${ }^{3}$ Professor, UFRPE/UAST, Serra Talhada-PE, thieres_freire@yahoo.com.br, sanddrabastos@yahoo.com.br

${ }^{4}$ Professor, PPGEA, UNIVASF, Juazeiro-BA, mario.miranda@univasf.edu.br

${ }^{(*)}$ Corresponding author

\section{ARTICLE INFO}

Article history:

Received 16 June 2017

Accepted 10 August 2017

\section{Index terms:}

net radiation

albedo

solar radiation

semiarid

\section{ABSTRACT}

The objective of this study was to analyze the daily and seasonal variation of the components of the radiation balance in a sugar cane crop irrigated by subsurface drip irrigation in the Submedio of the São Francisco Valley. For this, measurements of the incident global solar radiation (Rg), reflected radiation, photosynthetically active incident radiation (RFA), radiation balance (Rn) and components derived from the radiation balance, such as albedo and the coefficient of transmissivity (Kt) were obtained. An experiment with sugarcane, variety RB 92 579, was carried in Juazeiro-BA from November 2010 to October 2011. In daily terms, cloudiness conditions affected the components of the radiation balance, with the exception of long-wave irradiance on the surface under full soil cover conditions, and to a lesser extent the albedo, which also shows dependence on the solar angle inclination. On a seasonal scale, in the development stages I, II, III and IV, (Rn) represented, on average, 58, 65, 62 and 59\% of Rg. The rainfall and irrigation events, the $\mathrm{Rg}$ seasonality and the soil cover level influenced the components of the radiation balance and the albedo, which presented a mean value of $23 \%$. 